N 18, A NEW DAMAGE TOLERANT PM SUPERALLOY FOR HIGH TEMPERATURE

TURBINE DISCS

C. DUCROCQ, A. LASALMONIE, Y. HONNORAT

SNECMA - MATERIALS AND PROCESSES DPT - BP 81 - 91003 EVRY CEDEX

\title{
ABSTRACT
}

This paper describes the microstructure and the properties of $\mathrm{N} 18$. This new P.M. alloy was designed for application in high temperature turbine discs.

N 18 is strengthened by a high volume fraction of $\gamma^{\prime}(55 \%)$. We describe how the $\mathrm{N} 18$ composition was selected to fit the SNECMA requirements ; we show that it is possible in this alloy to control, the respective volume fraction of inter and intragranular $\gamma^{\prime}$, as well as the grain size by thermomechanical treatments; as compared to other P.M. superalloys such as Astroloy, IN 100 and René 95, N 18 offers a unique combination of tensile strength, creep resistance and damage tolerance. 
The development by SNECMA of jet engines with improved efficiency and specific power requires, for the turbine discs, up to $750^{\circ} \mathrm{C}$, the use of a 1 imited density forgeable $\mathrm{Ni}$ based superalloy which has, a good compromise of mechanicals properties :

- high yield strength $\left[\mathrm{R} 0,2>1000 \mathrm{MPa}\right.$ for $\left.\mathrm{T} \leqslant 750^{\circ} \mathrm{C}\right]$ so that the disc can tolerate overspeed without burst,

- high creep resistance,

- good damage tolerance : under cyclic deformation, the crack growth rate should be as low as possible even when environmental effects and hold timo under stress are taken into account.

Several P.M. superalloys fullfil the strength specification such as René 95, IN 100, MERL 76 and Astroloy. Unfortunately the crack growth rate is an increasing function of yield strength ( $f i g .1$ ) so that none of these alloys can satisfy the SNECMA goal, although the closest one is Astroloy.

As a consequence a research program was undertaken involving SNECMA, Lwo laboratories : ONERA and EMP, and an alloy producer : IMPHY S.A., to define and develop, a new P.M. alloy, at the industrial scale.

\section{EXPERIMENTAL TECHNIQUES}

The conception and development of the new alloy progressed in three phases :

PHASE A : laboratory scale : a systematic study of the microstructural properties relationships based on physical considerations was made. Small batches of powders (10-30 kg) were atomized by REP and compacted by HIP. 47 alloys derived from Astroloy and René 95 were prepared to optimize the following parameters in three steps :

1 - the carbon content

2 - the nature and amount of $\gamma$ and $\gamma^{\prime}$ forming elements

3 - the minor elements.

PHASE B : pilot scale : from the results of phase A, five compositions were selected for a more extensive characterization of mechanical properties and structural stability. The following fabrication route was used :

- atomization by rotating electrode process ( $50 \mathrm{~kg}$ )

- screening at 65 mesh $(224 \mu \mathrm{m})$

- compaction by HIP and isothermal forging.

The heat treatments were : a solutioning treatment ( $4 \mathrm{~h}$ at $15^{\circ} \mathrm{C}$ below the $\gamma^{\prime}$ solvus) followed by a cooling at $100^{\circ} \mathrm{C} / \mathrm{min}+700^{\circ} \mathrm{C} / 24 \mathrm{~h}$ air cooled $+800^{\circ} \mathrm{C} / 24 \mathrm{~h}$ air cooled.

The comparison was made with the help of the following tests :

- tensile deformation $\left(T \leqslant 750^{\circ} \mathrm{C}\right)$

- creep on smooth and notched specimens $\left(650^{\circ} \mathrm{C} \leqslant \mathrm{T} \leqslant 750^{\circ} \mathrm{C}\right)$; fatigue crack growth rate measurements at $650^{\circ} \mathrm{C}$ with hold time $300 \mathrm{~s}$.

PHASE C : industrial scale : the best composition (N 18) was argon atomized in the IMPHY S.A. plant. Several atomization batches of $100 \mathrm{~kg}$ were mixed to form large blends.

A blend of $300 \mathrm{~kg}$ of screened powders (diameter $<106 \mu \mathrm{m}$ ) was used for the $\mathrm{N} 18$ characterization. 
The composition range of the $\mathrm{N} 18$ family [1] is given in table 1 . The choice of the elements obeyed the following objectives :

- the peak strength of the $\gamma^{\prime}$ phase must be shifted toward high temperatures, - the intrinsic strength of the $\gamma$ matrix must be high.

\begin{tabular}{|c|c|c|c|c|c|c|c|c|c|c|c|}
\hline ALLOY & $\mathrm{Cr}$ & Co & Mo & A1 & $T i$ & no & $\mathrm{Hf}$ & Other & $\begin{array}{r}\mathrm{C} \\
\mathrm{ppm}\end{array}$ & $\begin{array}{r}B \\
\text { ppm }\end{array}$ & $\begin{array}{c}z r \\
p p m\end{array}$ \\
\hline $\begin{array}{c}\text { N } 18 \\
\text { Patent }\end{array}$ & $11-13$ & $8-17$ & $6-8$ & $4-5$ & $4-5$ & $\leqslant 1,5$ & $\leqslant 1$ & & $\leqslant 500$ & $\leqslant 500$ & $\leqslant 500$ \\
\hline $\begin{array}{c}\text { N } 18 \\
\text { this study }\end{array}$ & 11,5 & 15,7 & 6,5 & 4,35 & 4,35 & & 0,5 & & 150 & 150 & 300 \\
\hline IN 100 & 12,4 & 18,5 & 3,2 & 5,0 & 4,4 & & & $v: 0,8$ & 700 & 200 & 600 \\
\hline MERL 76 & 12,4 & 18,5 & 3,2 & 5,0 & 4,3 & 1,65 & 0,75 & & 250 & 200 & 450 \\
\hline RENE 95 & 13 & 8 & 3,6 & 3,5 & 2,5 & 3,5 & & $w: 3,5$ & 250 & 75 & 500 \\
\hline ASTROLOY & 14,6 & 16,6 & 5,0 & 4 & 3,5 & & & & 280 & 280 & 600 \\
\hline
\end{tabular}

Table 1 : composition (wt\%) of N18 and other high strength P.M. superalloys

\section{X'forming elements :}

The strenghtening capability of $\gamma$ 'can be improved by the addition of $\mathrm{Ta}$ or $\mathrm{Nb}$ (René 95). Because of its high density $\mathrm{Ta}$ was eliminated ; as for $\mathrm{Nb}$, it has the drawback of increasing the notch sensitivity and the high temperature fatigue crack - growth rate [see René 95 on fig. 1] , so that the maximum content of $\mathrm{Nb}$ was limited to 1,5 weight \%. As a consequence $\mathrm{Al}$ and $\mathrm{Ti}$ are the main $\gamma^{\prime}$ forming elements ; the required strength necessitates a volume fraction of $\gamma^{\prime}$ higher than 0,5 . The sum $A 1+T i$ was taken as 0,1 with a near unity ratio $\mathrm{Al} / \mathrm{Ti}$.

\section{$\gamma$ forming elements :}

Mo and $W$ are very efficient as high temperature solid solution slrengheners of $\gamma$. A detailed study (2) evinced that Mo should be preferred to $w$ :

- the partition ratio of Mo between $\gamma$ and $\gamma^{\prime}$ was twice that of $W$

- for a given $W+$ Mo content, the notch sensitivity during creep at $650^{\circ} \mathrm{C}$ increased drastically with the amount of $\mathrm{W}$, whereas the rupture time for smooth specimen was only slightly improved (fig. ?) ; moreover the need of keeping a low density was in favour of Mo.

Other elements :

The choice of the chromium content (11-13\%) gives to the $\mathrm{N} 18$ family a good oxydation resistance, without excessive precipitation of intragranular carbides, detrimental for the ductility. For the same reason a low carbon content is prefered. Some $\mathrm{Hf}(\leqslant 1 \%)$ is added to promote the formation of MC carbides without scavenging Mo, $\mathrm{Ti}$ and $\mathrm{Cr}$; thus $\mathrm{Hf}$ has an indirect effect on the strengthening; some Hf remains in solid solution within $\gamma$ and $\gamma^{\prime}$ and contributes directly to the strenghtening.

The composition range of the $\mathrm{N} 18$ family is given on table 1 ; on the same table is given the composition which was extensively tested : on table 2 its properties are compared with those of the reference commercial alloys. 
Fig.1 : Yield strength and fatigue crack growth rate at $650^{\circ} \mathrm{C}$ of $\mathrm{PM}$ alloys SNECMA results, except René 95[9]
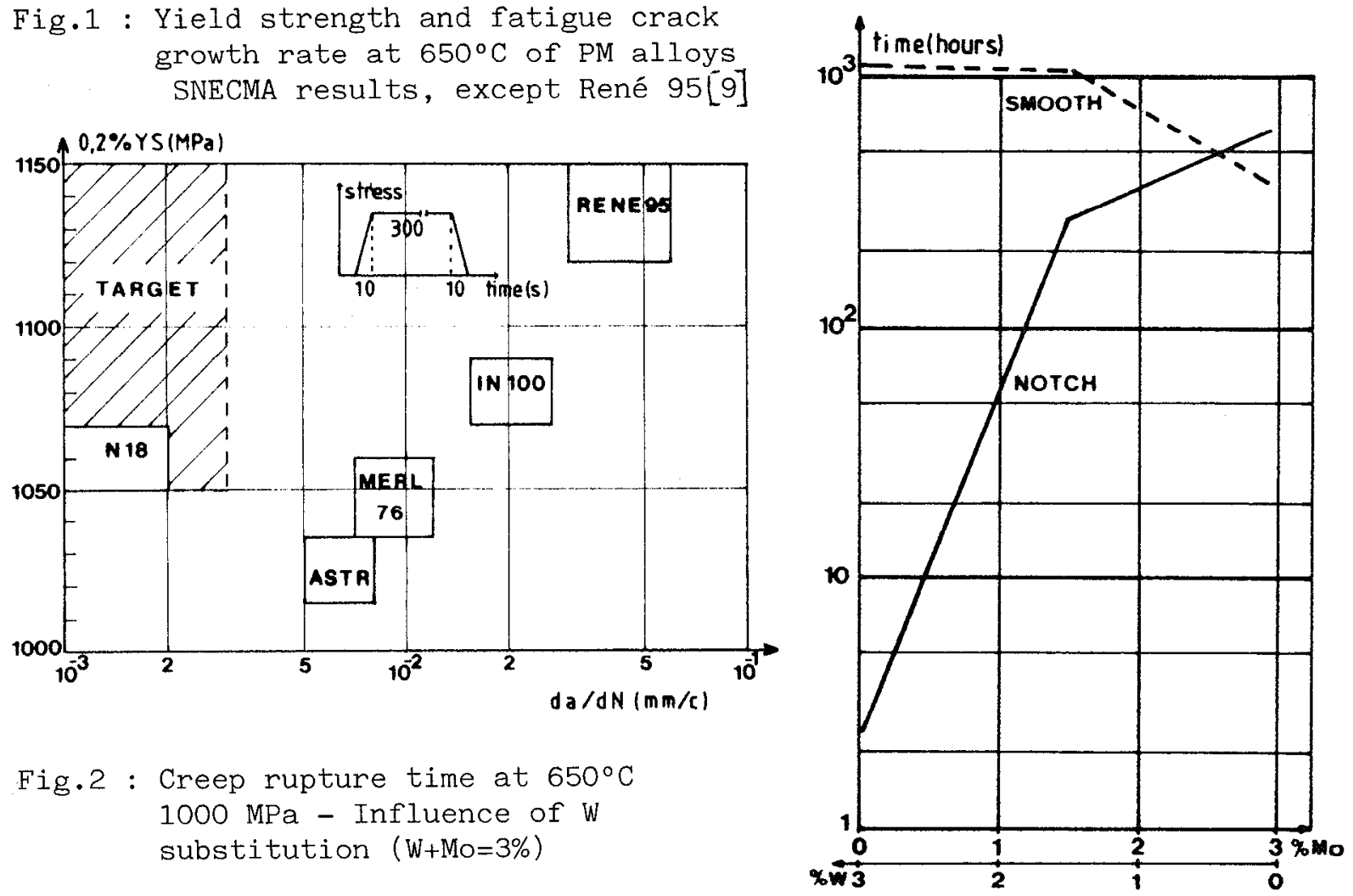

Fig.2 : Creep rupture time at $650^{\circ} \mathrm{C}$ $1000 \mathrm{MPa}$ - Influence of $\mathrm{W}$ substitution $(\mathrm{W}+\mathrm{Mo}=3 \%)$

\begin{tabular}{|l|c|c|c|c|c|}
\hline & Fraction $\gamma^{\circ}$ & solvus $\gamma^{\prime}$ & $\begin{array}{c}\text { Density } \\
\text { g/cm3 }\end{array}$ & Nv & Md \\
\hline IN 100 & $61 \%$ & $1185^{\circ} \mathrm{C}$ & 7,9 & 2,471 & 0,928 \\
\hline MERL 76 & $64 \%$ & $1190^{\circ} \mathrm{C}$ & 7,95 & 2,591 & 0,941 \\
\hline RENE 95 & $48 \%$ & $1155^{\circ} \mathrm{C}$ & 8,27 & 2,217 & 0,915 \\
\hline ASTROLOY & $45 \%$ & $1145^{\circ} \mathrm{C}$ & 8,0 & 2,357 & 0,926 \\
\hline N 18 & $55 \%$ & $1190^{\circ} \mathrm{C}$ & 8,0 & 2,361 & 0,932 \\
\hline
\end{tabular}

Table 2 : Comparison between $\mathrm{N} 18$ and commercial alloys INDUSTRIAL PROCESSING

\section{Powder production:}

In view of mechanical characterization IMPHY S.A. produced a $300 \mathrm{~kg}$ blend of $\mathrm{N} 18$ powder ; it was argon atomized, and then containerized in the clean rooms of IMPHY S.A. ; the transfer of powder in smaller extrusion containers was done in the clean rooms of SNECMA.

\section{Powder control :}

The present résults were obtained from powders smaller than $106 \mu \mathrm{m}$ (150 mesh) $50 \%$ of which was below $50 \mu \mathrm{m}$. The cleanliness was checked by the water elutriation procedure described in the SNECMA patent [3].

The cleanliness was equivalent to that of industrially produced Astroloy as shown in table 3 . The gas content of the powder was $86 \mathrm{ppm}$ oxygen and $34 \mathrm{ppm}$ nitrogen (compared to $65 \mathrm{ppm} \mathrm{O}$ and $30 \mathrm{ppm} \mathrm{N}$ for Astroloy powder). 


\begin{tabular}{|l|c|c|c|}
\hline S1ze of inclusions & N 18* & ASTFoLOY* & $\begin{array}{c}\text { Specif. } \\
\text { SNECMA }\end{array}$ \\
\hline $80<81 z e<106 \mu \mathrm{m}$ & 6 & 3 & $<20$ \\
\hline $63<$ size $<80 \mu \mathrm{m}$ & 8 & 6 & \\
\hline
\end{tabular}

- N $18 \quad 300 \mathrm{~kg} \otimes<106 \mu \mathrm{m}$ (150 mesh)

- Astrolor $2700 \mathrm{~kg} \emptyset<106 \mu \mathrm{m}$ (150 mesh)

Table 3 : Water elutriation results on $\mathrm{N} 18$ and Astroloy powders

Powder consolidation

Two routes were tested :

- compaction by HIP and conventional forging of $50 \mathrm{~kg}$ billets giving rise to a necklace structure,

- extrusion of $30 \mathrm{~kg}$ billets on the $4000 \mathrm{~T}$. SNECMA press and isothermal forging of $5 \mathrm{~kg}$ billets on the $600 \mathrm{~T}$. SNECMA press.

The second route proved to be better, because of an easier industrial practice and because of a better ultrasonic inspectability [4]. Small discs ( $\varnothing 170 \mathrm{~mm})$ were forged from bars $(\varnothing: 90 \mathrm{~mm})$. The heat treatments were similar to those given above for phase B ; several solutioning temperatures were tried, results are presented here for two cases :

$4 \mathrm{~h}$ at $1110^{\circ} \mathrm{C}$ giving a small grain size $(5 \mu \mathrm{m}$ ) (fig. $3 \mathrm{a}$ ) or solutioning $4 \mathrm{~h}$ at $1165^{\circ} \mathrm{C}$ giving a medium grain size (12 $\mu \mathrm{m}$ ) ( $\mathrm{fig} .3 \mathrm{~b}$ ).

In both cases the cooling rate after solutioning was $100^{\circ} \mathrm{C} / \mathrm{min}$ and the precipitation treatments were $700^{\circ} \mathrm{C} / 24 \mathrm{~h} \mathrm{A.C} .+800^{\circ} \mathrm{C} / 4 \mathrm{~h} \mathrm{A.C}$. For the medium grained alloy discs were forged at a reduced scale $(\varnothing 180 \mathrm{~mm})$ and bench tested (specially for overspeed resistance) at SNECMA (fig. 4).

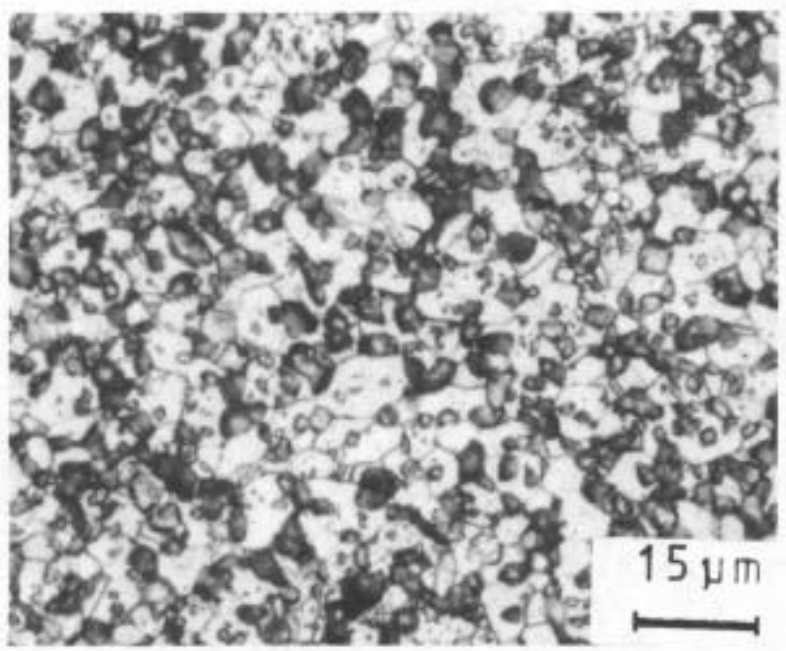

Fig. 3 a

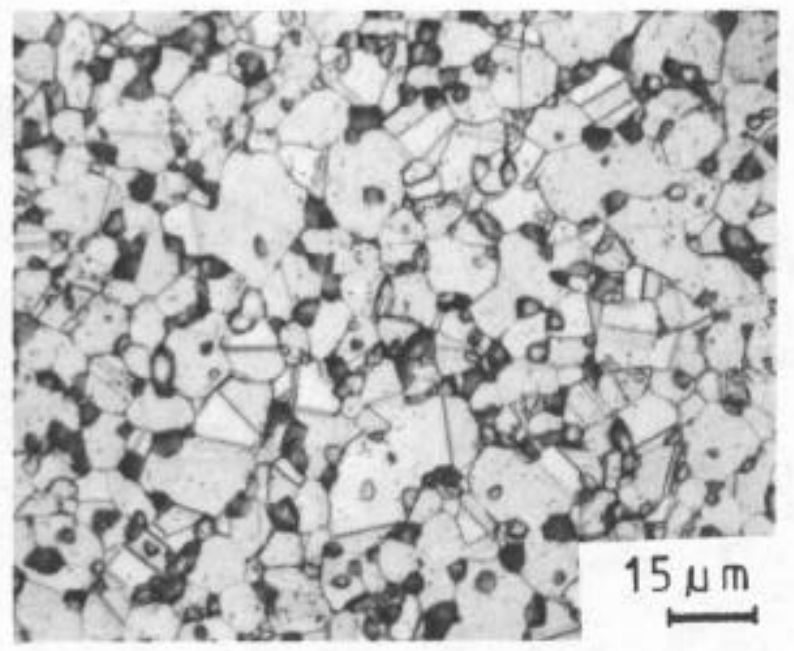

Fig. $3 \mathrm{~b}$

Fig. 3 : the two tested microstructures a) solutioning at $1110^{\circ} \mathrm{C}$

b) solutioning at $1165^{\circ} \mathrm{C}$

Superplasticity

$\mathrm{N} 18$ is superplastic at high temperature, for deformation rates smaller than $5.10^{-3} \mathrm{~s}^{-1}$. The strain rate sensitivity exponent is about 0,7 as in Astroloy (fig. 5) ; for a $5 \mu \mathrm{m}$ grain size, the flow stress is smaller than that of Astroloy and IN 100 ; this low flow stress allows the extrusion of larger bars for a given press. 


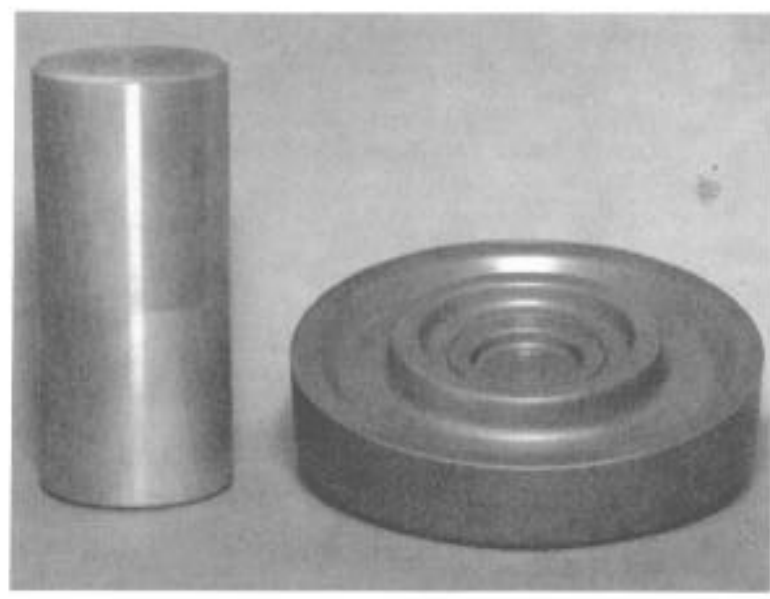

Fig. 4

Isothermally forged disc preform

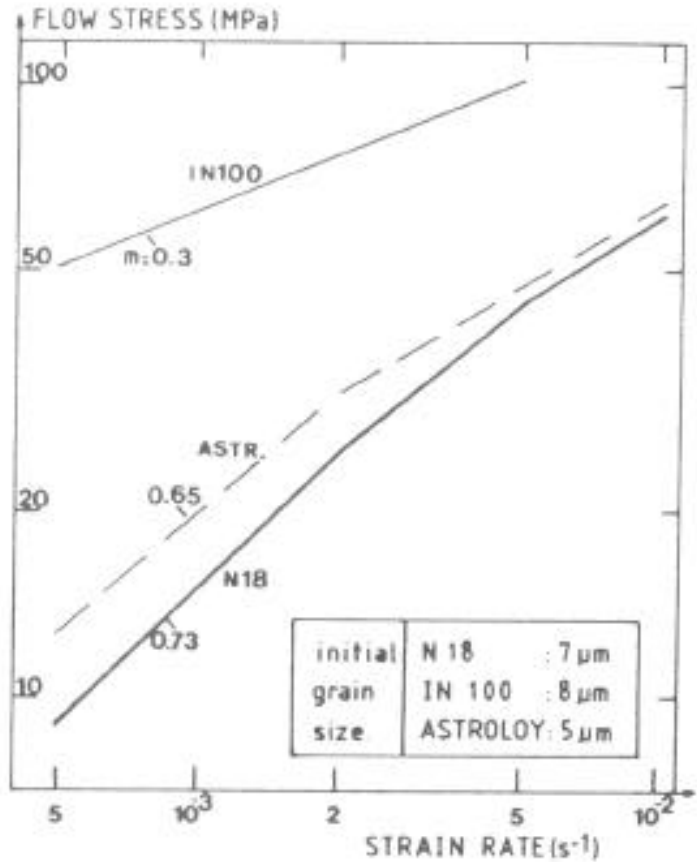

Fig.5 : flow stress of superplastic N18, IN 100[5] and Astroloy at $1100^{\circ} \mathrm{C}$

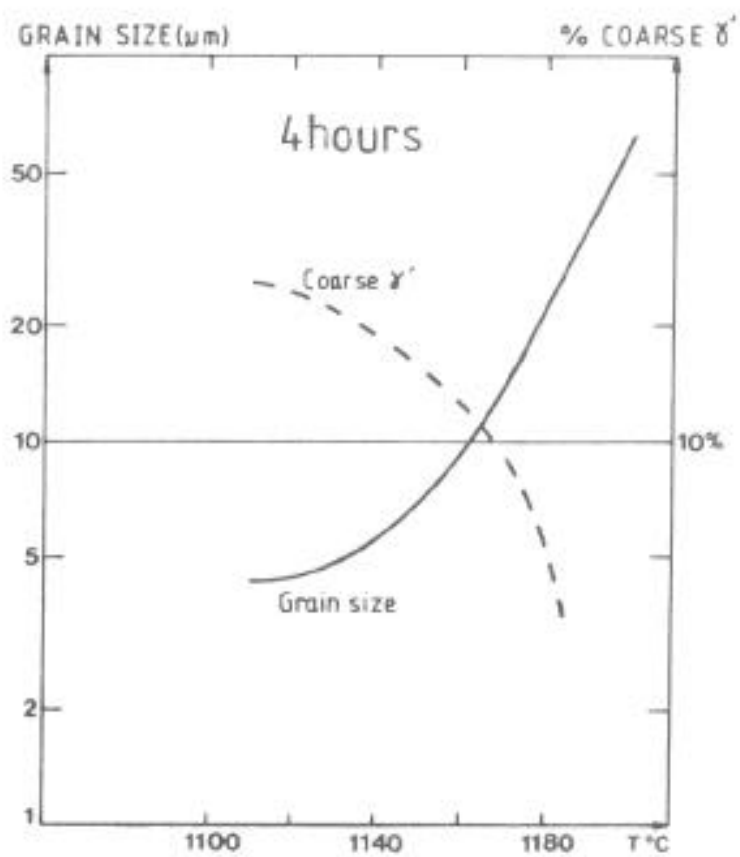

Fig. 6: Influence of N18 solutioning temperature on $f p$ and $d$

\section{MICROSTRUCTURE}

The main microstructural features which determine the mechanical properties are :

- the intergranular $X_{p}^{\prime}$ precipitates formed at high temperature ; their volume fraction and size are $f p$ and $d p$

- the intragranular $\chi^{\prime}$ precipitates formed during the heat treatments having a volume fraction $f s$ and a size ds

- the grain size - d - .

The ability to control these parameters is critical when searching a balance between a high strength at low temperature and low creep rates above $600^{\circ} \mathrm{C}$. For instance d must be small enough to induce a high Hall-Petch strengthening; on the contrary small d promote rapid grain boundary sliding during creep ; moreover it is well known that the crack growth rate at $650^{\circ} \mathrm{C}$ is a decreasing function of grain size [6].

Fig. 3 shows extruded - isoforged structure with the two different solutioning temperatures $\left(1110^{\circ} \mathrm{C}\right.$ and $1165^{\circ} \mathrm{C}$ ). In both cases the grain size is homogeneous. In high strength P.M. superalloys, the grain growth kinetics is very low below $1100^{\circ} \mathrm{C}$ and drastically rapid near or above the $\gamma^{\prime}$ solvus ; as a consequence 
grain size control by heat treatment is difficult in Astroloy ; in $N 18$ it is easier to obtain a grain size in the range $15 \mu \mathrm{m}-30 \mu \mathrm{m}$ due to the high $\gamma^{\prime}$ solvus (fig. 6). When the solutioning temperature increases from $1115^{\circ} \mathrm{C}$ to $1165^{\circ} \mathrm{C}$, the fraction $\mathrm{fp}$ decreases continuously from 0,25 to about 0,15 ; sin$c e f s+f p=0,55$, the fraction $f$ 's of intragranular $\gamma^{\prime}$ is an increasing function of the temperature.

The $\gamma^{\prime}$ size resulting from the standard heat treatments is ds $\simeq 0,13 \mu \mathrm{m}$ (fig. 7), whereas $d p \simeq 4 \mu m$; ds depends strongly on the cooling rate from solutioning but no systematic investigation of this parameter was made.

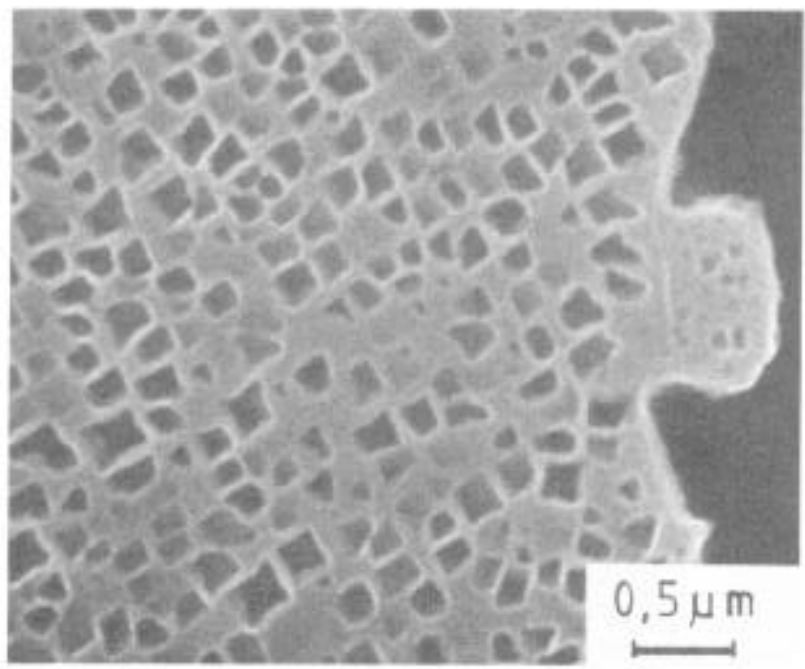

Fig. 7 : intragranular $\gamma^{\prime}$ after the standard precipitation treatment

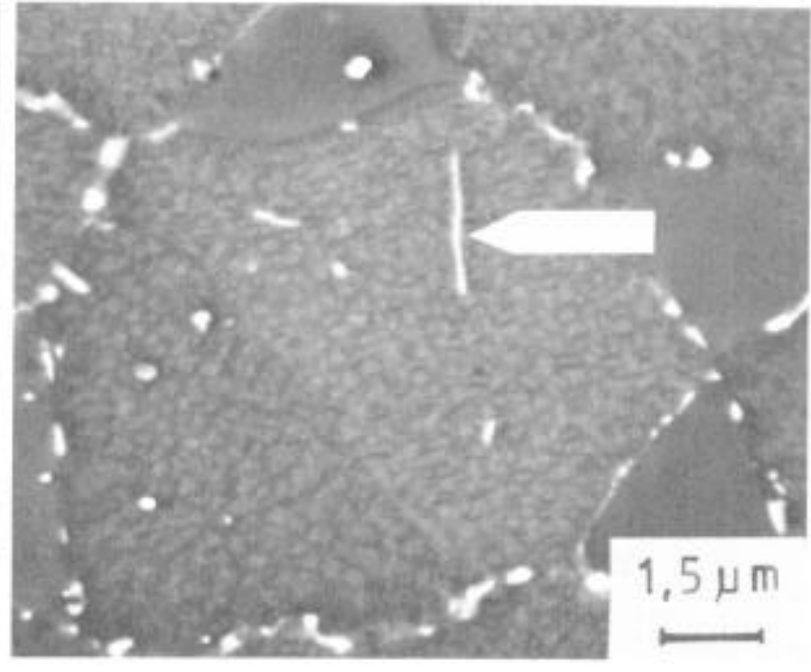

Fig.8 : intergranular carbides and platelet precipitation (arrow)

\section{THERMAL STABILITY}

The Nv [7] and Md [8] parameters are given in table 2 for $N 18$ and other P.M. superalloys. The stability of $\mathrm{N} 18$ as respect to T.C.P. phases (i.e. $\sigma$ phase) is equivalent to that of Astroloy. This was confirmed by microscopic observations on specimens annealed between $600^{\circ} \mathrm{C}$ and $800^{\circ} \mathrm{C}$. At $650^{\circ} \mathrm{C}$ a treatment of 3000 hours induced a precipitation of fine intergranular carbides but no $\sigma$ phase was found, at $700^{\circ} \mathrm{C}$ some rare intragranular platelets were observed after $600 \mathrm{~h}$; these platelets disappear above $850^{\circ} \mathrm{C}$; their length was about $1 \mu \mathrm{m}$ and thickness $0,1 \mu \mathrm{m}$ (fig. 8), they were enriched in Mo and $\mathrm{Cr}$ and were found to contain carbon ; there is however some ambiguity about their nature : from the diffraction patterns they can be $\mathrm{M}_{7} \mathrm{C}_{3}$ or $\mathbf{I}$. In $\mathbb{N} 18$ the precipitation of the platelets can be retarded by increasing the solutioning temperature. Up to $750^{\circ} \mathrm{C}$ the volume fraction of the platelets remains always small and does not seem to be detrimental for ductility.

No platelet but a much more abundant precipitation of carbides was observed in Astroloy annealed in the same conditions.

\section{MECHANICAL PROPERTIES}

\section{Tensile properties}

As explained before, the most extensive characterization was made on extruded iso forged structures, with grain sizes $5 \mu \mathrm{m}$ and $12 \mu \mathrm{m}$.

The tensile properties are ploted on fig. 9 and compared to Astroloy and IN $100($ grain size $=5 \mu \mathrm{m})$. N 18 has the highest rupture stress; its yield stress is intermediate between Astroloy and IN 100 up to $650^{\circ} \mathrm{C}$ but is less thermoactivated above $650^{\circ} \mathrm{C}$. 
The tensile properties below $650^{\circ} \mathrm{C}$ of $\mathrm{N} 18$ are almost insensitive to the grain size for the range $5 \mu \mathrm{m}-15 \mu \mathrm{m}$. Indeed, when the grain size goes from $5 \mu \mathrm{m}$ to $15 \mu \mathrm{m}$, the softening due to the Hall Petch mechanism is $\Delta \sigma_{1}=\mathrm{k}$ $\left(\mathrm{d}_{2}{ }^{-1 / 2}-\mathrm{d}_{1}-1 / 2\right)=-140 \mathrm{MPa}$ for a Hall-Petch constant $\mathrm{k}=0.7 \mathrm{MPa} \sqrt{\mathrm{m}}[10]$. It is balanced by an increase of the $\gamma^{\prime}$ s volume fraction ( $f$ s goes from 0,3 to $0,4)$ giving a strengthening $\Delta \sigma_{2} / \sigma_{2}=n \Delta f / f \quad[$ for a constant ds] $\cdot n-1 / 2$ if $\gamma^{\prime}$ is sheared and $n=1 / 2$ in the case of OROWAN bending so that $100 \mathrm{MPa}<$

$\Delta \sqrt{2}<150 \mathrm{MPa}$. The total variation $-40 \mathrm{MPa}<\Delta \sqrt{1}+\Delta \sqrt{2}<10 \mathrm{MPa}$, is inside experimental dispersion.

- The properties are given for a cooling rate $100^{\circ} \mathrm{C} / \mathrm{min}$ from the solution treatment. The yield stress can be modified by changing the cooling rate as shown in other alloys such as Astroloy (fig. 10).

- The ductility of $\mathrm{N} 18$ is always higher than 12 .
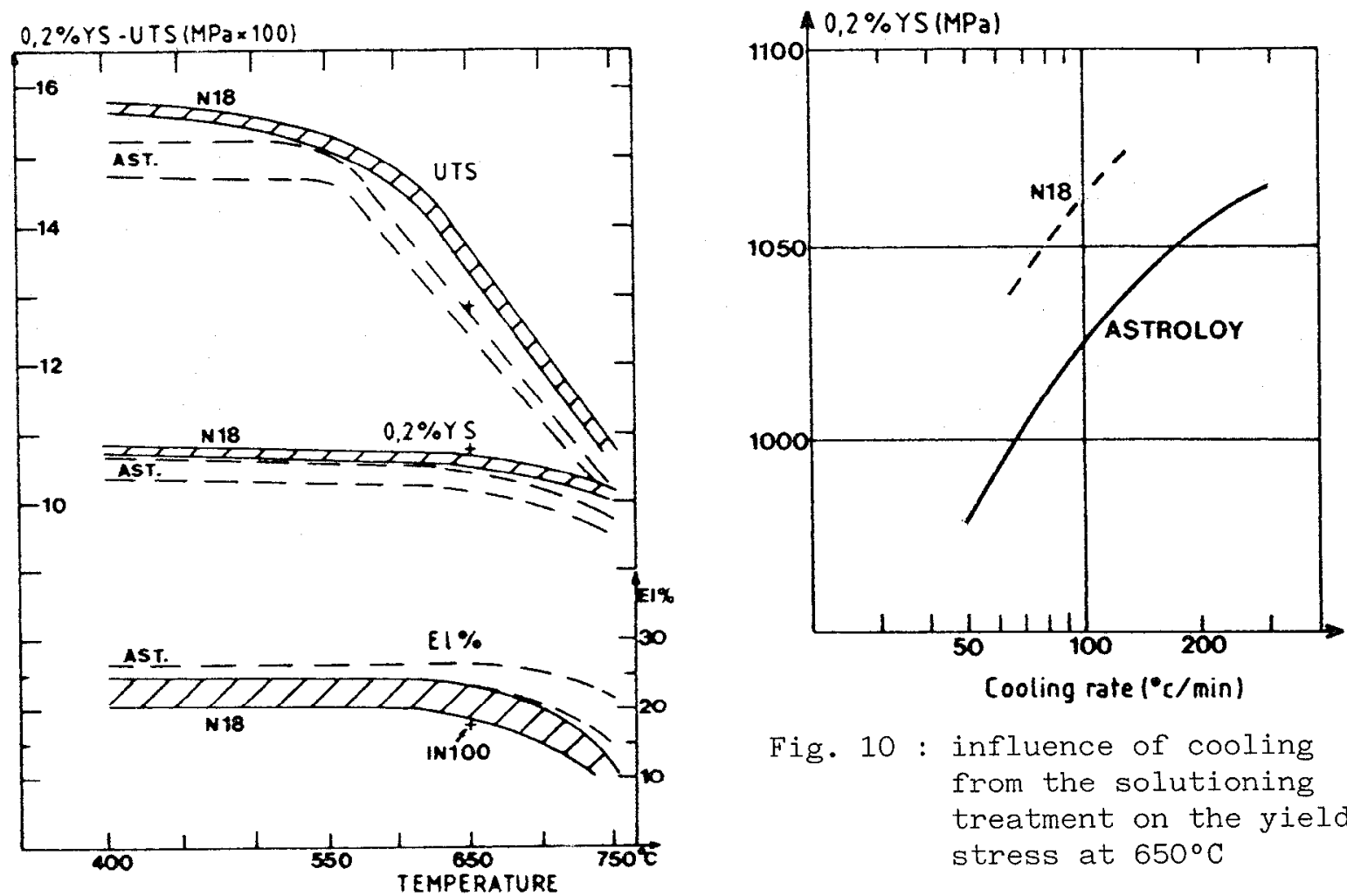

Fig. 10 : influence of cooling from the solutioning treatment on the yield stress at $650^{\circ} \mathrm{C}$

Fig. 9 : tensile properties of $\mathrm{N} 18$ Astroloy and IN 10

Creep properties $\left(600^{\circ} \mathrm{C}-750^{\circ} \mathrm{C}\right)$

In the usual Larson Miller plot, $\mathrm{N} 18(\mathrm{~d}=12 \mu \mathrm{m})$ is better than Astroloy and IN 100 (fig. 11). For a $5 \mu \mathrm{m}$ grain size the creep properties are about the samc as for Astroloy with a $5 \mu \mathrm{m}$ grain size; the creep ductility is about $7 \%$ in the all range of temperatures.

Low cycle fatigue and crack growth rate

Fatigue life was measured both is stress and strain controlled tests at $550^{\circ} \mathrm{C}-600^{\circ} \mathrm{C}$ and $650^{\circ} \mathrm{C}$.

High stress (or deformation) levels were used so that the rupture initiated always on surface inclusions (mainly alumina); the fatigue life was found to be the same as in Astroloy tested in identical conditions : for instance at $600^{\circ} \mathrm{C} \quad[f=0,5 \mathrm{~Hz}, \Delta \varepsilon t=1 \%(\mathrm{R} \varepsilon=0)]$ the number of cycles ot failure is $210^{3}$ for both alloys. The crack growth rate at $650^{\circ} \mathrm{C}$ with a dwell time of $300 \mathrm{~s}$ is given on fig. 12 ; da/dN follows the usual relatioship $\mathrm{da} / \mathrm{dN}=$ C. $\Delta \mathrm{K}^{2} \cdot 5^{\mathrm{g}}[\sigma]$ and is about half the rate observed in Astroloy which is one fo the most damage tolerant alloys. As shown on fig. 13 the rupture is in- 

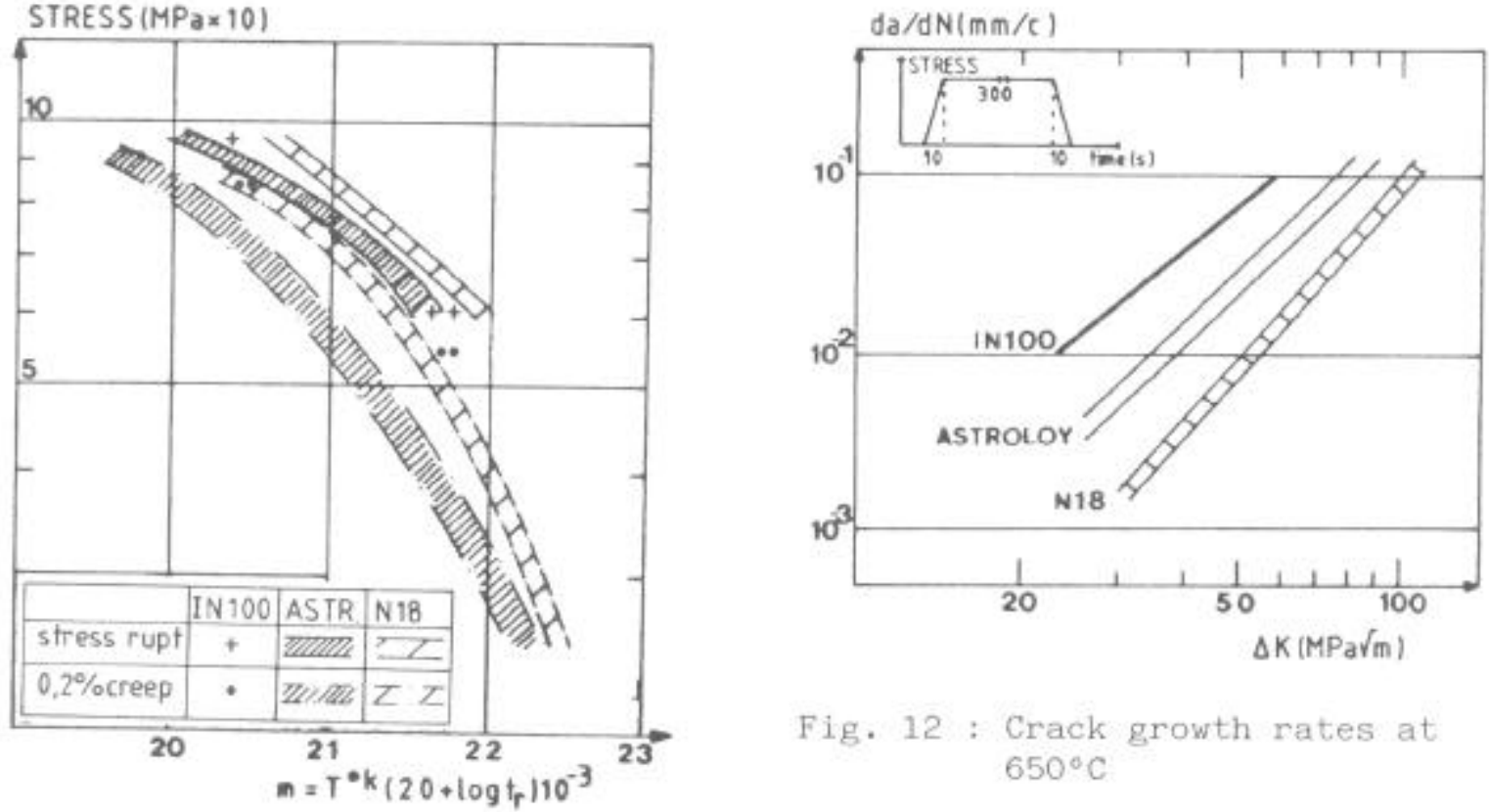

Fig. 12 : Crack growth rates at $650^{\circ} \mathrm{C}$

Fig. 11 : Larson Miller curve for creep deformation and creep rupture

Fig. 13 : Intergranular rupture at $650^{\circ} \mathrm{C}$ in $12 \mu \mathrm{m} N 18$

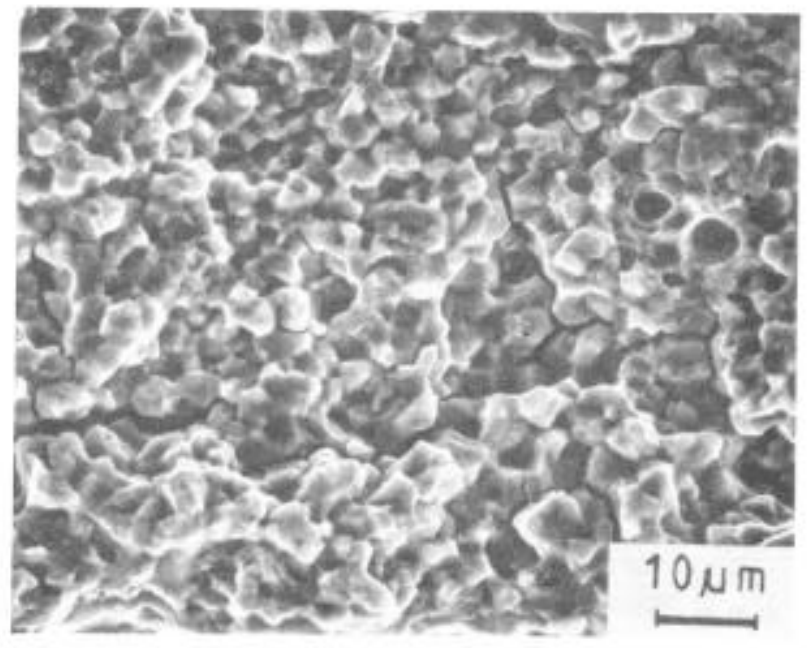

Fig. 14 : Minima design data at elevated temperature

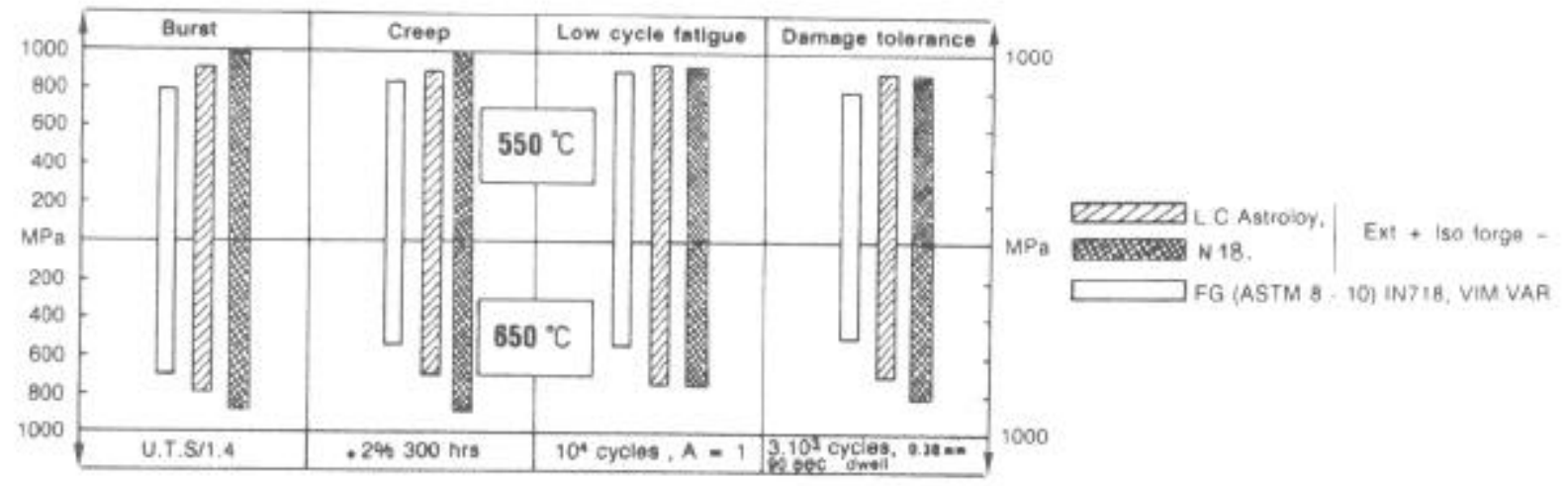


tergranular so that da/dN is unlikely to be strongly affected by the strengthening of the matrix ; the main advantage of $N 18$ is obviously in the possibility of getting a medium grain size $(10-20 \mu \mathrm{m})$ while keeping, at the same time, a high volume fraction of intergranulary'.

\section{$\underline{\text { CONCLUSION }}$}

Figure 14 summarizes the mechanical properties which are critical for the turbine disc designer. The figure shows clearly the superiority of $\mathrm{N} 18$ over Astroloy and fine grained IN 718 which are presently used by SNECMA for compressor discs fabrication.

N 18 is characterized by better creep properties and damage tolerance at $650^{\circ} \mathrm{C}$ combined with a high rupture strength ; the mechanical properties of this new P.M. alloy fall within the initial target (fig. 1) ; these properties are the result of casy grain size control and $\gamma^{\prime}$ morphology combined with optimum strengthening of the grain and of the grain boundaries. Several tons have now been extruded for bench testing of actual turbine discs.

\section{ACKNOWLEDGEMENTS}

We are grateful to DRET and STPA for rinancial support and to Dr J.L. STRUDEL (EMP), A. WALDER (ONERA) and J.H. DAVIDSON (IMPHY S.A.) for fruitfull collaboration.

\section{REFERENCES}

[1] C. Ducrocq, P. Lestrat, P. Paintendre, J.H. Davidson, M. Marty and

A. Walder - French patent n 8601604 (1986)

[2] M. Marty, A. Walder and C. Diot

P.M. Aerospace materials - Luzern Nov. 87

[3] R. Morbioli - J. Ney - French patent no 8310717 (1983)

[4] D.R. Chang, D.D. Krueger and R.A. Sprague Superalloy 1984 - Ed. by M. Coll, C.S. Kortovich, R.N. Bricknell W.H. Kent and J.F. Radavich

The metallurgical society of AIME (1984) - 245

[5] L.N. Moskovitz and al. : 2nd int. conf. on superalloys MCIP rep. 72-10, 1972, pp Z-1 to Z-25

[6] J. Gayda, R.V. Miner, Met. trans 14A (1983) 2302

[7] W.J. Boesch - Met.Progr. 86 (1964) - 109

[8] M. Morinaga, N. Yukawa, H. Ezaki Phil. Mag. A, 51 (1985) - 223

[9] R.A. Sprague Private communication

[10] A. Lasalmonie, J.L. Strudel

Journal Materials Science $21 \quad$ (1986) 1837 - 1852 